\title{
A Student Satisfaction Index Model of Chinese College Based on CSI
}

\author{
Xiangqing CHEN \& Ming YI \\ Foshan Polytechnic, Foshan, China \\ Lixia YU \\ Sichuan Normal University, Chengdu, China
}

\begin{abstract}
According to the specific situation of Chinese Higher Education, this article modifies SCSB, ACSI, ECSI, and CCSI and explores to construct a Student Satisfaction Index Model of Chinese College, including structural variables such as information, college image, student expectation, perceived quality, perceived cost, perceived value, student satisfaction, student Complaint and student loyalty.
\end{abstract}

KEYWORD: Customer Satisfaction Index; Student Satisfaction Measurement; Model; Higher Education

\section{INTRODUCTION}

There is investigation and studies on Satisfaction of College Students in the sixty's decade last century, America. After fifty years, it has developed as rather mature theory, system and method in the developed countries such as America and England. It is meaningful for education reform and resource scheme with determining and reviewing college students satisfaction by the people oriented and student oriented. However, it began late in such research area with determine and review inside in China. It makes against for upgrading Chinese College by lacking of determining and reviewing outside credibly. The author establishes a Study on Student Satisfaction Index Model of Chinese College and demonstrates it in theory basing on the characteristic of Chinese College Student and the relative research on Customer Satisfaction.

\section{SUMMARY}

In recent years, some scholars and colleges in China began to pay attention to investigation and studies on the satisfaction of Chinese college students, and made certain theoretical achievements and accumulated relevant practical experiences.

For the construction of the measurement model, Zhao Guojie and Zhang Tong used analytic hierarchy process to calculate the perceived quality scores of college students(Zhao Guojie et al. 2001); Zhao Guojie and Shi Xiaoming used American Customer Satisfaction Index model (ACSI) as reference(Fornell et al. 1992), to construct the Chinese higher education satisfaction measurement model and provide certain foundation for the follow up studies(Zhao Guojie et al. 2003); on the basis of the ACSI theory, Zhu Guofeng proposed some ideas on the construction of the Chinese higher education satisfaction index system(Zhu Guofeng et al. 2003); Zhao Yaohua and Han Zhijun set up the structural equation model for college customer satisfaction measurement, calculated the route coefficient of relevant structural variables and carried out empirical analysis on the relation between cause and effect(Zhao Yaohua et al. 2007); Yang Xue and Liu $\mathrm{Wu}$ used American Customer Satisfaction Index model (ACSI) as reference to set up a CHE-CSI model for Chinese higher education satisfaction index, mainly including customer expectation, perceived quality, perceived value, college image, customer satisfaction, customer trust, customer commitment, customer loyalty and other structural variables, and carried out empirical analysis on six colleges in Shenyang(Yang Xue et al. 2006); Liu Ximei set up higher vocational college student differential satisfaction measurement model based on the service "differential" theory(Liu Ximei, 2011); Liu Xinxue et al used structural equation method to carry out investigation and research on the life satisfaction of vocational college students(Liu Xinxue, 2011).

As for the measurement on practice, Fu Zhenfang carried out investigation and research from ten aspects on students from different colleges, mainly including college characteristics, college management, teachers and teaching, student service, college style, teaching atmosphere, study atmosphere, safety and security, logistics services and employment advices(Fu Zhenfang, 2004); Ji Xiaoyi and Huang Xiaoping set up a student 
satisfaction measurement index system based on the following six aspects: teaching team, teaching condition, teaching situation, sports and recreation activities, logistics assurance and self development (Ji Xiaoyi et al. 2004); according to the study of Wei Huafei and Fang Wenmin, the college customer expectation is mainly shown on teaching management, teaching quality, employment opportunity, campus environment, logistics service and college popularity, including eighteen items and contents(Wei Huifei et al. 2005); Chang Yaping et al set up an measurement system based on the College Student Satisfaction Scale of Laurie Schreiner and Stephanie Juiliard, which consists of 9 second level indexes and 49 third level indexes(Chang Ya-ping et al. 2007); Li Ke's study focused on the study satisfaction of college students from teaching qualification, teaching management, teaching organization, study conditions, self development and services(Li Ke, 2007); Shen Dan and Zhou Jieru used KANO model to carry out student satisfaction study from 16 aspects including knowledge acquisition, capacity upgrade, individual development, logistics service and management, campus life, entertainment and health of students (Chen Dan et al. 2011); Wang Yashuang et al used the "National College Student Study Condition Online Investigation Platform" to carry out study satisfaction investigation to over 17,000 students in China(Wang Yashuang, 2012).

Although the researchers confirmed the importance of measurement on student satisfaction, doubtlessly there were deficiencies. Some scholars criticized the studies on student satisfaction measurement for lack of systematic strategy and theory support, deficiency on methodology especially measuring tools, lack of consensus on definition, measuring method and other factors, leading to the diversity of study objective and method on student satisfaction, which is not beneficial to the cross comparison among colleges of the same country or colleges of different countries or different cultures. The writer believed that the previous measurement model is set up either based on ACSI only, using its definition and scale, without fully reflecting the characteristics of students in China, or under the restriction of measurement on perceived quality of student, without taking full consideration of the influence relations of student expectation and other relevant factors. Besides, the previous theories overwieght the needs of micro view, involving too many variables and questions, lack of sufficient theory support, and it is difficult to carry out large size and large scale measurement and unbeneficial to cross comparison.

\section{MODEL DESCRIPTION}

The comparison standard used during the forming process of customer satisfaction includes expectancy disconfirmation mode, need disconfirmation mode, perceived performance mode and fairness mode, among which "expectancy disconfirmation" is the most popular customer satisfaction measurement mode. Thus, the measurement on college student satisfaction carried out by the writer is mainly based on the expectancy disconfirmation mode, the introduction of student expectation variable and the assumption that student expectation has direct influence on perceived quality and student satisfaction (Oliver, 1980). As for new college students, as they are lack of information about their school before entering college, alternative expectation is used in the study if the student expectation towards their school is insufficient.

As for the relations between customer value and customer satisfaction, it is proven by researches and studies in the academic circles that customer satisfaction depends on customer value. Perceived value as a structural variable is introduced to the existing measurement models, for example, in the American Customer Satisfaction Index Model (ACSI); customer satisfaction is the center of the model, which depends jointly on perceived quality, perceived value and customer expectation (Fornell et al. 1996). However, the relations among perceived quality, perceived value and customer expectation are a little bit confused in the existing models. On one hand, the comparison between perceived value and customer expectation affects customer satisfaction, on the other hand, perceived quality and customer expectation will form customer value which will further affect customer satisfaction. Despite scholars have different opinions on customer value; most scholars agree that the core of perceived value is the weighing between perceived gain and perceived loss or the comparison between perceived quality and perceived cost, which is different from the comparison between perceived value and customer expectation. Therefore, the writer introduces a hidden variable of perceived cost based on the original comparison between perceived quality and customer expectation to affect perceived value through the comparison between perceived quality and perceived cost, in order to affect customer satisfaction. The application of relatively independent expectancy disconfirmation mode and perceived value mode is beneficial to clearly understand the contribution of each other towards customer satisfaction.

"Corporate Image" was introduced to more and more customer satisfaction measurement models as a structural variable based on the consideration that corporate image had important influence on customer expectation, customer satisfaction and 
customer loyalty, which was proven by the empirical studies performed by domestic and foreign scholars. For example, Yang Xue and Liu Wu et al introduces college image in the college satisfaction measurement model and comes to the conclusion through empirical studies that college image has the greatest influence on student satisfaction (Yang Xue et al. 2006). Therefore, college image variable is introduced to this model based on the assumption that college image has direct influence on student expectation, student satisfaction and student loyalty.

The student's perception of the college image is formed based on the information provided by the media, school and alumnus as well as the student's judgment based on his/her cognitive level. Thorough and effective information will have great influence on the right decision made by student (Chen Xiangqing, 2007). The student's impression on a college (specialty) is built based on the information received, and expectation towards different colleges (specialties) is formed accordingly. Therefore, information as a structural variable is introduced to this model based on the assumption that information has direct influence on college image and student expectation.

As for the result of customer satisfaction, generally the customer satisfaction will increase the customer loyalty, and customer dissatisfaction will lead to customer complaint. The writer believed that with the rapid development of information technology and arriving individuation era, the life and thinking methods of people have changed greatly. There are more student complaints, and the good settlement of complaint will become more and more important. Therefore, customer complaint is introduced to this model as a variable based on the assumption that customer complaint has direct influence on customer loyalty.

\section{MODEL CONSTRUCTION}

\subsection{Definition model and measurement index}

Based on the assumption of the said customer satisfaction process, the writer has set up a definition model for college student satisfaction index measurement. The model consists of 9 structural variables: information $\xi_{1}$, perceived cost $\xi_{2}$, student expectation $\eta_{1}$, perceived quality $\eta_{2}$, college image $\eta_{3}$, perceived value $\eta_{4}$, student satisfaction $\eta_{5}$, student complaint $\eta_{6}$ and student loyalty $\eta_{7}$, among which, information and perceived cost are two exogenous variables and the others are endogenous variables. The whole measurement system is composed of four levels of indexes, the abovementioned 9 structural variables are used as second level measurement indexes, corresponding to 27 third level indexes (observable variables), and extending to fourth level indexes, i.e. questions on the questionnaire, as shown in table 1.

Table 1. Chinese College Student Satisfaction Measurement Index System.

\begin{tabular}{|c|c|c|}
\hline & $\begin{array}{l}\text { structural } \\
\text { variable }\end{array}$ & observable variable \\
\hline \multirow{9}{*}{$\begin{array}{l}\text { College } \\
\text { Student } \\
\text { Satisfaction } \\
\text { Index }\end{array}$} & $\begin{array}{l}\text { Information } \\
\xi 1\end{array}$ & $\begin{array}{l}\text { Sufficiency of information } \mathrm{x}_{1}, \\
\text { Authenticity of information } \mathrm{x}_{2}\end{array}$ \\
\hline & $\begin{array}{l}\text { Perceived } \\
\text { cost } \xi 2\end{array}$ & $\begin{array}{l}\text { Perceived admission cost } \mathrm{x}_{3} \text {, } \\
\text { Perceived tariff cost } \mathrm{x}_{4}, \text { General } \\
\text { perceived cost } \mathrm{x}_{5}\end{array}$ \\
\hline & $\begin{array}{l}\text { Student } \\
\text { expectation } \\
\eta 1\end{array}$ & $\begin{array}{l}\text { Hardware quality expectation } y_{1} \text {, } \\
\text { Software quality expectation } y_{2} \text {, } \\
\text { Total quality expectation } y_{3}, \text { Cost } \\
\text { expectation } y_{4} \text {; }\end{array}$ \\
\hline & $\begin{array}{l}\text { Perceived } \\
\text { quality } \eta 2\end{array}$ & $\begin{array}{l}\text { General perception of product } \\
\text { quality } \mathrm{y}_{5} \text {, Perception of product } \\
\text { quality reliability } \mathrm{y}_{6} \text {, Perception of } \\
\text { product quality customization } \mathrm{y}_{7}, \\
\text { Perception of service quality } \mathrm{y}_{8} \text { : }\end{array}$ \\
\hline & $\begin{array}{l}\text { College } \\
\text { image } \eta 3\end{array}$ & $\begin{array}{l}\text { College popularity } \mathrm{y}_{9}, \text { College } \\
\text { reputation } \mathrm{y}_{10} \text {, General college } \\
\text { image } \mathrm{y}_{11} ;\end{array}$ \\
\hline & $\begin{array}{l}\text { Perceived } \\
\text { value } \eta 4\end{array}$ & $\begin{array}{l}\text { Perceived value of achievements } \\
\text { compared to education service } \\
\text { received } \mathrm{y}_{12}, \text { Perceived value of } \\
\text { tuition paid compared to education } \\
\text { service received } \mathrm{y}_{13} ;\end{array}$ \\
\hline & $\begin{array}{l}\text { Student } \\
\text { satisfaction } \\
\eta 5\end{array}$ & $\begin{array}{l}\text { Satisfaction compared to } \\
\text { expectation } \mathrm{y}_{14} \text {, Satisfaction } \\
\text { compared to desire } \mathrm{y}_{15} \text {, Satisfaction } \\
\text { compared to other competitor } \mathrm{y}_{16}, \\
\text { General satisfaction } \mathrm{y}_{17} \text {; }\end{array}$ \\
\hline & \begin{tabular}{|l|} 
Student \\
complaint $\eta 6$
\end{tabular} & $\begin{array}{l}\text { Complaint in private } \mathrm{y}_{18} \text {, Complaint } \\
\text { in public } \mathrm{y}_{19} \text {; }\end{array}$ \\
\hline & $\begin{array}{l}\text { Student } \\
\text { loyalty } \eta 7\end{array}$ & $\begin{array}{l}\text { Possibility of recommending to } \\
\text { others } y_{20} \text {, Endurance capacity to } \\
\text { the change of admission cost } y_{21}, \\
\text { Endurance capacity to the change of } \\
\text { tariff } y_{22}\end{array}$ \\
\hline
\end{tabular}

The questionnaire is designed by combining domestic and foreign mature scales with certain innovation. For example, it evaluates student expectation through quality expectation and cost expectation, evaluates perceived cost through admission score perception, tuition cost perception and total cost perception, and evaluate student loyalty through the possibility of recommending to others, the endurance capacity to the change of admission score and the endurance capacity to the change of tariff, etc.

\subsection{The mathematical expression of model}

Based on the above-mentioned college student satisfaction measurement definition model, the writer sets up a corresponding structural equation model, which includes two parts, i.e. structural model and measuring model. The structural model mainly describes the relations among various structural variables, and the measuring model mainly 
describes the relation between observable variable and structural variable.

\subsection{Preparing the new file with the correct template}

Copy the template file B2ProcA4.dot (if you print on A4 size paper) or B2ProcLe.dot (for Letter size paper) to the template directory. This directory can be found by selecting the Tools menu, Options and then by tabbing the File Locations. When the Word programme has been started open the File menu and choose New. Now select the template B2ProcA4.dot or B2ProcLe.dot (see above). Start by renaming the document by clicking Save as in the menu Files. Name your file as follows: First three letters of the file name should be the first three letters of the last name of the first author, the second three letters should be the first letter of the first three words of the title of the paper (e.g. this paper: balpcc.doc). Now you can type your paper, or copy the old version of your paper onto this new formatted file.

\subsubsection{Structural model}

The structural model for college student satisfaction measurement is as follows:

$\eta=\mathrm{B} \eta+\Gamma \xi+\zeta$

Among which,

$\xi$ is the vector of structural exogenous variable;

$\eta$ is the vector of structural endogenous variables

$B$ is the coefficient matrix of the effect of endogenous variable versus endogenous variable;

$\Gamma$ is the coefficient matrix of the effect of exogenous variable versus exogenous variable;

$\zeta$ is the vector of potential error.

\subsubsection{Measuring model}

The mathematic form of the measuring model for college student satisfaction is as follows:

$\mathrm{X}=\Lambda_{\mathrm{X}} \xi+\delta \quad \mathrm{Y}=\Lambda_{\mathrm{Y}} \eta+\varepsilon$

Among which,

$\mathrm{X}$ is the vector of observable exogenous variable;

$\mathrm{Y}$ is the vector of observable endogenous variables;

$\Lambda \mathrm{x}$ is the regression coefficient or the loading matrix of $\mathrm{X}$ to $\xi$;

$\delta$ is the vector composed by the measurement error of $\mathrm{X}$;

$\Lambda y$ is the regression coefficient or the loading matrix of $Y$ to $\eta$; $\varepsilon$ is the vector composed by the measurement error of $Y$.

\section{CONCLUSION}

There is a new study on Student Satisfaction Index model of Chinese college established beyond the core of the traditional Student Satisfaction Index with great creation. It not only draws lessons from the studies of Student Satisfaction abroad, but also creates according to the behavior characteristic of native college student. It is perfectly created with the introduction of information and perceived cost exogenous variables, the joint influence of perceived cost and perceived quality on perceived value. However, the new measurement model of Student Satisfaction Index is an idealized study. Further study for leading in the related variable and the relationship between correlation variables is expected.

\section{REFERENCES}

[1] CHANG Yaping, HOU Xiaoli, XIU Yan-yang. The Research and Evaluation of Chinese High School Student Satisfaction Measurement. Journal of Higher Education, 2007(9):82-87

[2] CHEN Dan, ZHOU Jieru. The Research of Chinese College Education Customer Satisfaction - the application of KANO Model in College Education. Journal of Changchun University of Science and Technology (Social Sciences Edition), 2011(2):99-102

[3] CHEN Xiangqing. A New Measurement Model of Customer Satisfaction Index. Economic Survey, 2007(3):118-120

[4] Fornell C. A National Customer Satisfaction Barometer: The Swedish Experience. Journal of Marketing, 1992, 56:1-21.

[5] Fornell C, Johnson M D, Eugene W, etc. The American Customer Satisfaction Index: Nature, Purpose, and Findings Journal of Marketing, 1996, 60: 7-18.

[6] JI Xiaoyi Huang Xiaoping. The Research of Higher Education Service and Satisfaction. Higher Educational Research in Areas of Communications, 2005(4):29-32

[7] LIU Wu, Yang Xue. The Model and the Application Chinese Higher Education Customer Satisfaction index. Liaoning Education Research, 2006(10):7-10

[8] LIU Ximei.The Theory of differentiation on Student Satisfaction in Higher Vocational Education. Vocational Education Research, 2011 (01):69-71

[9] Oliver, R.L. A cognitive model of the antecedents and consequences of satisfaction decisions, Journal of Marketing Research, 1980, 17:460-469.

[10] WANG Yashuang. The Research of Chinese Higher Vocational College Student Satisfaction Research-Base on 2011"the Study Situation Survey of Chinese Student",. China Higher Education Research, 2012 (7):85-89 